Check for updates

Cite this: RSC Adv., 2019, 9, 29998

Received 25th July 2019

Accepted 17th September 2019

DOI: 10.1039/c9ra05782j

rsc.li/rsc-advances

\section{Magnetic molecularly imprinted polymers for the detection of aminopyralid in milk using dispersive solid-phase extraction $\uparrow$}

\author{
Yahui He,,$^{* a b}$ Sijia Tan,,$^{\text {b }}$ A. M. Abd El-Aty, (D) ${ }^{\text {cd }}$ Ahmet Hacımüftüoğlu ${ }^{d}$ \\ and Yongxin She $\mathbb{D}$ *b
}

A method for dummy molecular imprinting-magnetic dispersive solid-phase extraction (MI-MDSPE) coupled with liquid chromatography-tandem mass spectrometry (LC-MS/MS) was developed for the selective determination of aminopyralid in milk. The magnetic material and polymers were combined via a series of modifications in $\mathrm{Fe}_{3} \mathrm{O}_{4}$. $\mathrm{Fe}_{3} \mathrm{O}_{4} @ \mathrm{QSiO}_{2}-\mathrm{NH}_{2} @ \mathrm{QMIP}, \mathrm{Fe}_{3} \mathrm{O}_{4} @ \mathrm{aSiO}_{2}-\mathrm{COOH} @ \mathrm{MIP}$ and two types of aminopyralid-specific magnetic molecularly imprinted polymers (MMIPs) were prepared on the surface of magnetic nanoparticles modified with amino and carboxyl groups. The morphology and magnetic properties of the polymer were characterized. $\mathrm{Fe}_{3} \mathrm{O}_{4} \mathrm{QSSO}_{2}-\mathrm{NH}_{2} \mathrm{QMIP}$ exhibits not only good dispersibility and magnetic properties, but also an outstanding recognition pattern to the target analyte. Adsorption experiments demonstrated that $\mathrm{Fe}_{3} \mathrm{O}_{4} @ \mathrm{CSiO}_{2}-\mathrm{NH}_{2} @ \mathrm{MIP}$, with a high specific surface area and fast mass transfer rate, had a higher affinity than $\mathrm{Fe}_{3} \mathrm{O}_{4} \mathrm{CSiO}_{2}-\mathrm{COOH}(\mathrm{MIP}$ towards aminopyralid. Under the optimized MI-MDSPE conditions, the method had good linearity $\left(R^{2}>0.9972\right)$, excellent recoveries $(83.3-90 \%)$, and good precision (relative standard deviations (RSDs) $<12.6 \%$ ). This method has limits of detection (LOD) and quantification (LOQ) of 0.231 and $0.77 \mu \mathrm{gg}^{-1}$, respectively, indicating that these MMIPs can be used to analyse trace levels of aminopyralid in real samples.

\section{Introduction}

Aminopyralid is a synthetic auxin herbicide with a pyridine ring and carboxylic acid functional group. The mechanism of action of this synthetic hormone herbicide is similar to that of a growth hormone. ${ }^{1}$ Aminopyralid exerts highly efficient and selective weed removal since it can be quickly absorbed by the stems and leaves of plants and interrupt plant growth, causing rapid death..$^{2,3}$ Despite its low toxicity and high herbicidal activity, concerns have been raised ${ }^{4}$ because its improper use may cause negative impacts on human health. Research has shown that aminopyralid taken up by livestock through animal feed causes irreversible damage to human kidneys, because it exists as an exogenous anti-nutritional factor in the animal-

${ }^{a}$ Beijing Technology and Business University, 100048, P. R. China. E-mail: hyh@btbu. edu.cn; Fax: +86-1068985456; Tel: +86-1068985456

${ }^{b}$ Institute of Quality Standards \& Testing Technology for Agro-Products, Chinese Academy of Agricultural Sciences, Beijing 100081, P. R. China. E-mail: sheyongxin@ caas.cn; Fax: $+86-1082106567 ;$ Tel: $+86-1082106513$

'Department of Pharmacology, Faculty of Veterinary Medicine, Cairo University, 12211-Giza, Egypt

${ }^{d}$ Department of Medical Pharmacology, Medical Faculty, Ataturk University, 25240Erzurum, Turkey

$\dagger$ Electronic supplementary information (ESI) available. See DOI: 10.1039/c9ra05782j

$\ddagger$ Yahui He and Sijia Tan contributed equally to this article. derived foods. ${ }^{5}$ In China, standard rule GB 2763-2016 stipulates a maximum residue limit (MRL) of only $0.1 \mathrm{mg} \mathrm{kg}^{-1}$ for aminopyralid in barley, wheat, oats, and triticale, and there are no relevant limits set for animal-derived foods. Considering the low MRL of aminopyralid in milk, $0.02 \mathrm{mg} \mathrm{kg}{ }^{-1}$, set by the Codex Alimentarius Commission (CAC), an efficient pretreatment method and detection protocol for this herbicide in milk is of great importance. ${ }^{6}$

The analytical methodologies applied for the determination of aminopyralid in different matrices has been reviewed. For instance, liquid chromatography-tandem mass spectrometry (LC-MS/MS) ${ }^{7}$ and gas chromatography coupled with electron capture detection (GC-ECD) $)^{8}$ have been developed for determination of aminopyralid in vegetables and soil. Traditional sample pretreatment procedures, solid-phase extraction (SPE), and quick, easy, cheap, effective, rugged, and safe "QuEChERS" method were used in association with these chromatographic methods. However, these pretreatment methods have drawbacks of low selectivity and adsorption capacity, resulting in the inability to enrich trace amounts of target analytes from complex matrices.

As a promising separation technology, molecular imprinting techniques (MITs) involve predetermined molecular structures and specific recognition. Molecularly imprinted polymers (MIPs) with specific cavity structures are developed based on "the antigen and antibody" and "the lock and key" hypotheses. 
MIPs are tailored according to the target molecules. Advantages such as good stability, strong affinity, high selectivity, and low costs enable MIPs to be used in a wide range of applications in agriculture, environmental analysis, medicine, and other areas. $^{10}$

Two disadvantages of MIPs are that the template molecules cannot be completely cleaned and the mass transfer resistance is high; these issues have substantially reduced the amount of polymer that can be adsorbed. ${ }^{\mathbf{1 1}}$ Molecular imprinting using a dummy template that is similar in structure to the target molecules has eliminated false positive results caused by template leakage. ${ }^{12}$ Moreover, magnetic molecular imprinting has demonstrable advantages for sample pretreatment, such as a large specific surface area, low resistance to mass transfer, and high separation speed. ${ }^{13}$ Magnetic nanoparticles (MNPs) have the unique properties of nanocrystals, such as general small size effects, superparamagnetism, and surface effects, ${ }^{\mathbf{1 4}}$ and can be modified by active functional groups, such as $-\mathrm{COOH},-\mathrm{OH}$, and $-\mathrm{NH}_{2}$, to enable facile combination with MITs for use in sample pretreatment. However, MNPs exhibit a strong aggregation tendency and are easily oxidized in air, so materials including silica, surfactants, octadecylsilane, and others have been used to modify MNPs to overcome these shortcomings. ${ }^{15,16}$ Magnetic molecularly imprinted polymers (MMIPs) are prepared on the surface of a magnetic carrier using surface imprinting to distribute the imprinted sites on the surface of the MIP. ${ }^{17,18}$

Magnetic dispersive solid-phase extraction (MDSPE) based on separation with a magnetic sorbent and an external magnetic field can eliminate the need for a centrifugation step, shorten the separation time for the target molecules from solution, and reduce the loss of liquid and solid during the separation. ${ }^{19-21}$ In molecular imprinting-magnetic dispersive solid-phase extraction (MI-MDSPE), a MIP is synthesized on the surface of functionalized MNPs, which are then added to sample matrices containing target analytes for clean-up. After shaking the mixture, the MMIP that adsorbs the target substance is isolated from the solution using an external magnetic field. ${ }^{22,23}$ Compared with other pretreatment methods, MI-MDSPE combines the quick separation of magnetic particles and special selectivity of MIPs and has high specificity and simple method procedures.

In the present study, a novel MIP using picloram as a dummy template was successfully imprinted on the surface of $\mathrm{Fe}_{3}$ $\mathrm{O}_{4} @ \mathrm{SiO}_{2}-\mathrm{NH}_{2}$ for the specific adsorption of aminopyralid. The characteristics and binding tendency of the MMIP were investigated. By optimizing a range of conditions for MI-MDSPE, the MMIP was applied for the determination of aminopyralid in milk by dispersive SPE coupled with LC-MS/MS.

\section{Experimental}

\subsection{Chemicals and reagents}

Aminopyralid and picloram (purity > 99\%) were obtained from Dr Ehrenstorfer GmbH (Augsburg, Germany). 4-Vinylpyridine (4-VP) was purchased from Alfa Aesar (Massachusetts, USA). Trimethylolpropane trimethacrylate (TRIM), 1-ethyl-3-(3- dimethylaminopropyl)carbodiimide (EDC), and $N$-hydroxysuccinimide (NHS) were procured from Sigma-Aldrich (St. Louis, CA, USA). 2-2'-Azobisisobutyronitrile (AIBN) was acquired from Merck (Darmstadt, Germany). Iron(II) chloride tetrahydrate $\left(\mathrm{FeCl}_{2} \cdot 4 \mathrm{H}_{2} \mathrm{O}\right)$, iron(III) chloride hexahydrate $\left(\mathrm{FeCl}_{3} \cdot 6 \mathrm{H}_{2} \mathrm{O}\right)$, tetraethyl orthosilicate (TEOS), (3-aminopropyl)triethoxysilane (APTES), poly(ethylene glycol)bis(carboxymethyl) ether, and ammonium hydroxide were purchased from Beijing Chemical Co. (Beijing, China). Methanol (MeOH), acetonitrile (MeCN), $n$ hexane, and formic acid were of HPLC grade and supplied by Thermo Fisher Scientific (Waltham, MA).

\subsection{Instrumentation}

Milk samples were analysed with an Agilent HPLC system (1200 series, Agilent Technologies, USA) coupled with a triple quadrupole mass spectrometer (AB2000, AB SCIEX, USA) equipped with an electrospray ionization (ESI) source. HPLC analysis was performed on a Waters 2695 Alliance HPLC system (Waters Corporation, Milford, MA, USA) equipped with a diode array detector (DAD). X-ray diffraction (XRD) measurements used to determine the crystal structure of the nanoparticles were performed on a D-Max 2200 VPC diffractometer (Rigaku, Tokyo, Japan). Fourier transform infrared (FT-IR) spectroscopy (Philips PU9800, Philips Analytical, Cambridge, UK) was used to characterize the polymers. The hysteresis loop of magnetic compounds was measured using a vibrating sample magnetometer (VSM, LakeShore 7407, OH, USA).

\subsection{Chromatographic conditions}

HPLC and LC-MS/MS were used to determine the adsorption performance of the MIPs and the amount of aminopyralid in the milk samples, respectively. In HPLC, aminopyralid was separated on a Waters Sunfire $\mathrm{C}_{18}$ column $(4.6 \times 150 \mathrm{~mm}$, particle size of $5 \mu \mathrm{m})$. The mobile phase consisted of $0.1 \%$ formic acid in ultrapure water (A) and methanol (B). Gradient elution was carried as follows: $10 \% \mathrm{~B}$, held for $1 \mathrm{~min}$, increased to $80 \% \mathrm{~B}$ in $7 \mathrm{~min}$, held for $1 \mathrm{~min}$, decreased to $10 \%$ in $8.1 \mathrm{~min}$, and held for $1.9 \mathrm{~min}$ to equilibrate the column. The flow rate of the mobile phase was maintained at $1 \mathrm{~mL} \min ^{-1}$ and the column temperature was set at $28^{\circ} \mathrm{C}$. The injection volume was $20 \mu \mathrm{L}$.

The analytical column for LC-MS/MS was a Waters XSelect HSS T3 column $(2.1 \times 150 \mathrm{~mm}$, particle size of $5 \mu \mathrm{m})$. The mobile phase was composed of ultrapure water (A) and methanol (B) with a flow rate of $0.3 \mathrm{~mL} \mathrm{~min}^{-1}$. Gradient elution was carried out as follows: increased from $40 \%$ to $60 \%$ B in $2 \mathrm{~min}$, increased to $90 \% \mathrm{~B}$ in $8 \mathrm{~min}$, held for $2 \mathrm{~min}$, decreased to $40 \% \mathrm{~B}$ in $10.1 \mathrm{~min}$, and held for $4.9 \mathrm{~min}$ to equilibrate the column. The injection volume was $5 \mu \mathrm{L}$.

\subsection{MS/MS conditions}

A mass spectrometer equipped with an ESI source was operated in multiple reaction monitoring (MRM) mode to determine aminopyralid in positive ionization mode. The conditions of the ESI source were as follows: the ion source temperature was $450{ }^{\circ} \mathrm{C}$, and the gas pressures of the collision-activated 
dissociation (CAD), curtain gas (CUR), ion source gas 1 (GS1), and ion source gas 2 (GS2) were 8, 40, 50, and 50 psi, respectively. The qualitative ion pair $(\mathrm{m} / \mathrm{z})$ consisted of 207.0 and 189 , and the quantitative ion pair $(\mathrm{m} / \mathrm{z})$ consisted of 207.0 and 161 . The declustering potential (V) and collision energy (eV) were $39.29,29.2$, and 18.41, respectively.

\subsection{Synthesis and modification of $\mathrm{Fe}_{3} \mathrm{O}_{4}$ magnetic nanoparticles}

The magnetic $\mathrm{Fe}_{3} \mathrm{O}_{4}$ nanoparticles were synthesized by coprecipitation. ${ }^{24}$ Briefly, $\mathrm{FeCl}_{2} \cdot 4 \mathrm{H}_{2} \mathrm{O}(0.86 \mathrm{~g})$ and $\mathrm{FeCl}_{3} \cdot 6 \mathrm{H}_{2} \mathrm{O}(2.35$ g) were dissolved in $100 \mathrm{~mL}$ of ultrapure water in a three-neck flask and vigorously stirred under a nitrogen atmosphere at $60-70{ }^{\circ} \mathrm{C}$. As the temperature was elevated to $80{ }^{\circ} \mathrm{C}, 10 \mathrm{~mL}$ of a $25 \%$ ammonia solution was added, and the mixture was stirred vigorously for $30 \mathrm{~min}$. Then, $0.1 \mathrm{~g}$ of sodium citrate was added to increase the dispersion of the nanoparticles, and stirring was continued for another $30 \mathrm{~min}$. After finishing the reaction, the mixture was cooled to room temperature, and then the black magnetic precipitates were isolated from the solvent by a permanent magnet and washed several times alternating between deionized water and ethanol until the $\mathrm{pH}$ of the eluent approached neutral.

The $\mathrm{Fe}_{3} \mathrm{O}_{4} @ \mathrm{SiO}_{2}$ nanocomposites were synthesized according to the hydrolysis of a silylation reagent as follows. The prepared $\mathrm{Fe}_{3} \mathrm{O}_{4}$ (approximately $1 \mathrm{~g}$ ) was dispersed in $50 \mathrm{~mL}$ of ethanol via ultrasound. Then, $25 \mathrm{~mL}$ (approximately $0.5 \mathrm{~g}$ of $\mathrm{Fe}_{3} \mathrm{O}_{4}$ ) of the solution of the magnetic nanoparticles dissolved in ethanol was measured and separated by magnet. After discarding the ethanol supernatant, $20 \mathrm{~mL}$ of double-distilled water and $100 \mathrm{~mL}$ of ethanol were added to the solution and sonicated for $30 \mathrm{~min}$. Afterward, $1 \mathrm{~mL}$ of ammonium hydroxide (25\%, w/w) and $2 \mathrm{~mL}$ of TEOS were added to the mixture in a dropwise manner. The mixture was stirred at room temperature for $24 \mathrm{~h}$.

The $\mathrm{Fe}_{3} \mathrm{O}_{4} @ \mathrm{SiO}_{2}$ particles were modified by amino groups. Briefly, $1.5 \mathrm{~mL}$ of APTES was added to the above $\mathrm{Fe}_{3} \mathrm{O}_{4} @ \mathrm{SiO}_{2}$ reaction solution and stirred. The stirring continued at $40{ }^{\circ} \mathrm{C}$ for $24 \mathrm{~h}$. The obtained $\mathrm{Fe}_{3} \mathrm{O}_{4} @ \mathrm{SiO}_{2}-\mathrm{NH}_{2}$ was collected by a magnet and thoroughly washed with ethanol several times.

Similar to the production of $\mathrm{Fe}_{3} \mathrm{O}_{4} @ \mathrm{SiO}_{2}-\mathrm{NH}_{2}$, carboxyl groups were grafted on the $\mathrm{Fe}_{3} \mathrm{O}_{4} @ \mathrm{SiO}_{2}$ nanocomposites. The $\mathrm{Fe}_{3} \mathrm{O}_{4} @$ @$\mathrm{SiO}_{2}-\mathrm{NH}_{2}$ nanoparticles were dispersed in $0.01 \mathrm{mmol} \mathrm{L}^{-1} \mathrm{PBS}$ buffer with a pH of 7.4. After being completely dissolved, $80 \mu \mathrm{L}$ of poly(ethylene glycol)bis(carboxymethyl) ether, $5 \mathrm{~mL}$ of $10 \mathrm{mg} \mathrm{mL}$ EDC, and $5 \mathrm{~mL}$ of $10 \mathrm{mg} \mathrm{mL}^{-1}$ NHS were added. Subsequently, the obtained dispersion was mechanically stirred at room temperature for $8 \mathrm{~h}$, and the precipitate was collected by a magnet, repeatedly washed with ethanol, and dried in a vacuum.

\subsection{Procedures for the preparation of MMIPs}

A series of polymers were prepared to investigate the effect of adsorption amount and polymerization ratio of the functional monomer and crossing-liker as shown in Table S1. $\dagger$ The results showed that the optimal molar ratio of template to functional monomer and cross-linker was $1: 6: 6$. The synthesis of MIPs with a molar ratio of picloram/4-VP/TRIM =1:6:6 is described as follows. The dummy template picloram $(0.2 \mathrm{mmol})$ was dissolved in $30 \mathrm{~mL}$ of methanol, and then the functional monomer 4-VP (1.2 mmol) was added. This mixture was stirred for $30 \mathrm{~min}$ on a shaker table to form the template-monomer complex. Then, $\mathrm{Fe}_{3} \mathrm{O}_{4} @ \mathrm{SiO}_{2}-\mathrm{NH}_{2}(100 \mathrm{mg})$ dissolved in $10 \mathrm{~mL}$ of methanol, the cross-linker TRIM $(1.2 \mathrm{mmol})$ and the initiator AIBN $(50.0 \mathrm{mg}$ ) were added to the above mixture solution and ultrasonically mixed for $5 \mathrm{~min}$. The reaction mixture was purged with nitrogen and stirred at $60{ }^{\circ} \mathrm{C}$ for $24 \mathrm{~h}$. After polymerization, the polymers were collected magnetically and washed with methanol/acetic acid (80:20, v/v) until no precursor was detected by HPLC. Finally, the MMIPs were rinsed with methanol until neutral $\mathrm{pH}$ was achieved and dried under vacuum at $50{ }^{\circ} \mathrm{C}$ for $24 \mathrm{~h}$.

Magnetic nonimprinted polymers (MNIPs) were synthesized using the same method as above, except the template picloram was omitted.

For comparison, $\mathrm{Fe}_{3} \mathrm{O}_{4} @ \mathrm{SiO}_{2}-\mathrm{COOH} @ \mathrm{MIP}$ was prepared by the same procedure, except $\mathrm{Fe}_{3} \mathrm{O}_{4} @ \mathrm{SiO}_{2}-\mathrm{COOH}$ replaced $\mathrm{Fe}_{3}$ $\mathrm{O}_{4} @ \mathrm{SiO}_{2}-\mathrm{NH}_{2}$ in the polymerization process.

\subsection{Measurement of kinetic adsorption and adsorption isotherm curves}

Dynamic and static equilibrium adsorption experiments were conducted to evaluate the adsorption capacity of different polymers. $^{25}$ Ten milligrams each of MMIP or MNIP was dispersed in a $2 \mathrm{~mL}$ centrifuge tube containing $1 \mathrm{~mL}$ of methanol solution with aminopyralid at $15 \mu \mathrm{g} \mathrm{mL}{ }^{-1}$ and shaken for different times $(0.5,1,1.5,2,4,6$, and $8 \mathrm{~h})$. Similarly, for the static experiments, $10 \mathrm{mg}$ of MMIP or MNIP was mixed with $1 \mathrm{~mL}$ of aminopyralid in methanol at various concentrations $(5$, $10,15,20,30,50,100$, and $\left.150 \mu \mathrm{g} \mathrm{mL}^{-1}\right)$. After shaking for $1 \mathrm{~h}$, the samples were collected by a magnet. The residual aminopyralid in the supernatant was detected by HPLC. The amount of aminopyralid adsorbed on the MMIP and MNIP particles $(Q$, $\mu \mathrm{g}^{-1}$ ) was calculated by eqn (1):

$$
Q=\left(C_{\mathrm{o}}-C_{\mathrm{e}}\right) V / m
$$

where $C_{\mathrm{o}}\left(\mu \mathrm{g} \mathrm{mL}^{-1}\right)$ and $C_{\mathrm{e}}\left(\mu \mathrm{g} \mathrm{mL}^{-1}\right)$ represent the target concentration in the supernatant initially and at equilibrium, respectively. $V(\mathrm{~mL})$ is the solution volume, and $m(\mathrm{mg})$ is the mass of MMIP or MNIP particles.

The subsequent Scatchard analysis of the MMIP was evaluated. The Scatchard curve was plotted using the Scatchard equation, $Q / C_{\mathrm{e}}=\left(Q_{\max }-Q\right) / K_{\mathrm{d}}$, and the dissociation constant $\left(K_{\mathrm{d}}\right)$ and the maximum absorption of binding sites $\left(Q_{\max }\right)$ were calculated.

The selective adsorption of the MMIP was evaluated using chloramphenicol as the target with the same method.

\subsection{Optimization of MDSPE}

Ten milligrams of $\mathrm{Fe}_{3} \mathrm{O}_{4} @ \mathrm{SiO}_{2}-\mathrm{NH}_{2} @ \mathrm{MIP}$ was added to a $5 \mathrm{~mL}$ centrifuge tube as a sorbent for dispersive SPE, and $1 \mathrm{~mL}$ of $50 \mu \mathrm{g}$ $\mathrm{L}^{-1}$ aminopyralid solution was added to the tube and shaken to extract the target compound. Finally, the mixture was separated by 

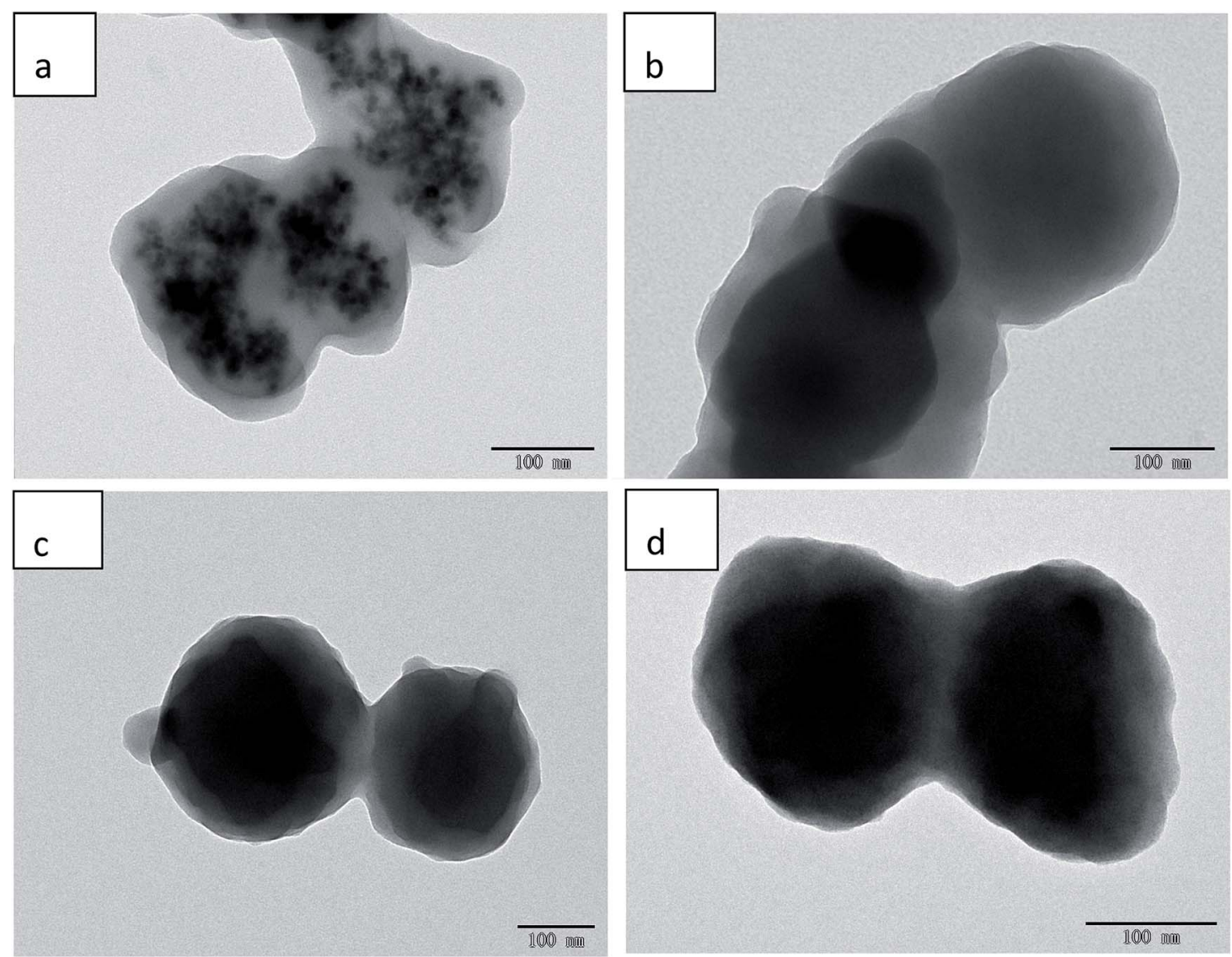

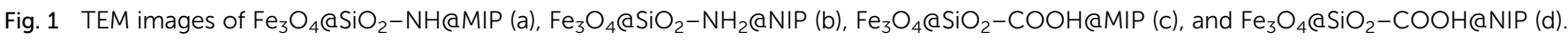

a magnet, and the eluent was analysed using LC-MS/MS. Based on the analyte recovery, the extraction solution, extraction time, $\mathrm{pH}$, elution solvent, and elution time were optimized.

\subsection{Analysis of milk samples}

Milk samples ( $2 \mathrm{~g}$ ) spiked with aminopyralid standard solutions $\left(10,20\right.$, and $\left.50 \mu \mathrm{g} \mathrm{L}^{-1}\right)$ were first extracted using acetonitrile (10
$\mathrm{mL}$ ) for $5 \mathrm{~min}$. Anhydrous magnesium sulfate (4 g) and sodium chloride $(1 \mathrm{~g})$ were added to remove water from the milk sample. The solution was centrifuged at $5000 \mathrm{rpm}$ for $10 \mathrm{~min}$, and then $5 \mathrm{~mL}$ of the supernatant was transferred to a new centrifuge tube containing $2 \mathrm{~mL}$ of $n$-hexane saturated with acetonitrile to remove the upper fat layer. $\mathrm{Fe}_{3} \mathrm{O}_{4} @ \mathrm{SiO}_{2}-\mathrm{NH}_{2} @ \mathrm{MIP}(10.0 \mathrm{mg})$ was suspended in $1 \mathrm{~mL}$ of the above solution, and then the

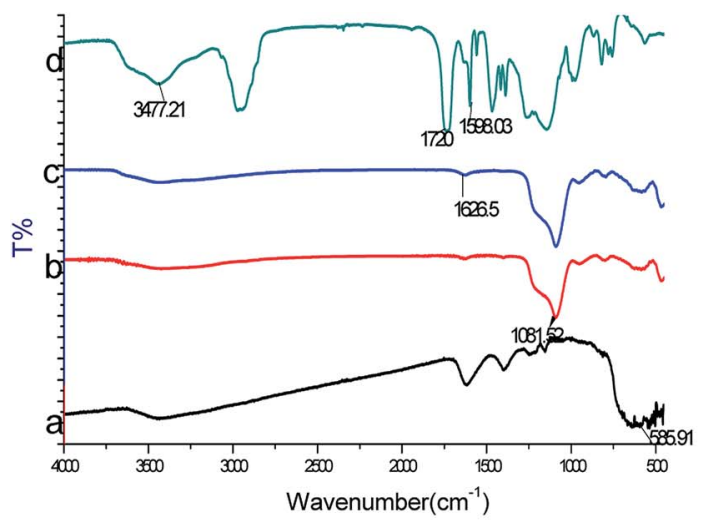

A

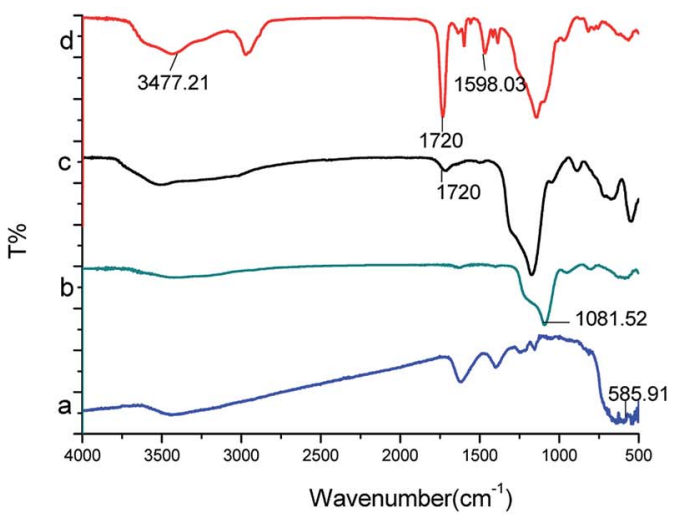

B

Fig. 2 (A) FT-IR spectra of $\mathrm{Fe}_{3} \mathrm{O}_{4}$ (a), $\mathrm{Fe}_{3} \mathrm{O}_{4} \mathrm{aSiO}_{2}$ (b), $\mathrm{Fe}_{3} \mathrm{O}_{4}\left(\mathrm{aSiO}_{2}-\mathrm{NH}_{2}\right.$ (c) and $\mathrm{Fe}_{3} \mathrm{O}_{4}\left(\mathrm{aSiO}_{2}-\mathrm{NH}_{2}\left(\mathrm{aMIP}\right.\right.$ (d); (B) FT-IR spectra of Fe $3 \mathrm{O}_{4}$ (a), $\mathrm{Fe}_{3} \mathrm{O}_{4} @ \mathrm{aSiO}_{2}$ (b), $\mathrm{Fe}_{3} \mathrm{O}_{4} \mathrm{aSiO}_{2}-\mathrm{COOH}$ (c), and $\mathrm{Fe}_{3} \mathrm{O}_{4} \mathrm{aSiO}_{2}-\mathrm{COOH} @ \mathrm{MIP}$ (d). 


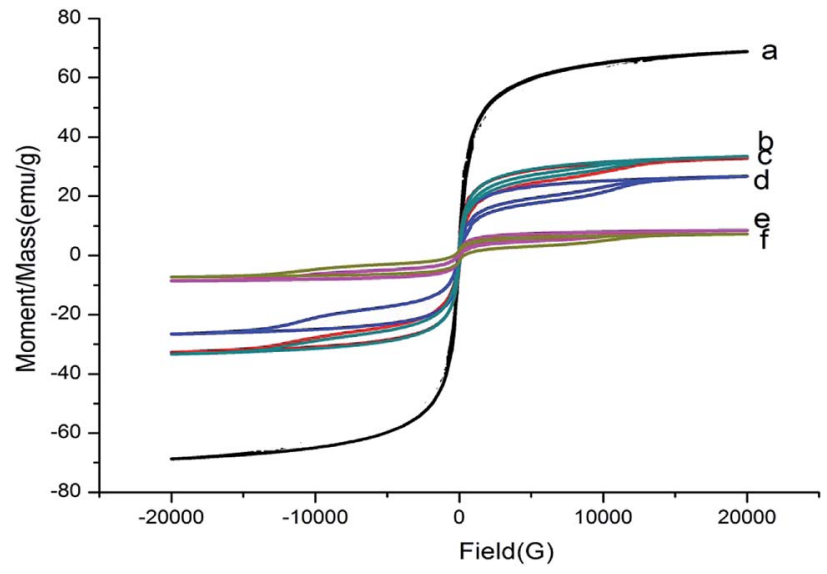

Fig. 3 Hysteresis loop of $\mathrm{Fe}_{3} \mathrm{O}_{4}(\mathrm{a}), \mathrm{Fe}_{3} \mathrm{O}_{4} \mathrm{aSiO}_{2}(\mathrm{~b}), \mathrm{Fe}_{3} \mathrm{O}_{4} \mathrm{aSiO}_{2}-\mathrm{NH}_{2}$ (c), $\mathrm{Fe}_{3} \mathrm{O}_{4} @ \mathrm{aSiO}_{2}-\mathrm{COOH}$ (d), $\mathrm{Fe}_{3} \mathrm{O}_{4} \mathrm{QSiO}_{2}-\mathrm{NH}_{2} @ \mathrm{aMIP}(\mathrm{e}), \mathrm{Fe}_{3} \mathrm{O}_{4} \mathrm{QSiO}{ }_{2}-$ COOHaMIP (f).

supernatants were adjusted to $\mathrm{pH}$ 5. After shaking for $10 \mathrm{~min}$, the target was eluted using $3 \mathrm{~mL}$ of methanol for $5 \mathrm{~min}$ on a shaker table. The eluent was collected by a magnet and analysed using LC-MS/MS. Each sample was analysed in triplicate.

\section{Results and discussion}

\subsection{Characterization of MMIPs and MNIPs}

The prepared samples were characterized by transmission electron microscopy (TEM), FT-IR spectroscopy, XRD, and VSM. The particle size and morphology of the MMIPs and MNIPs can be clearly observed by TEM (Fig. 1). The TEM images of $\mathrm{Fe}_{3} \mathrm{O}_{4}, \mathrm{Fe}_{3} \mathrm{O}_{4} @ \mathrm{SiO}_{2}-$ $\mathrm{COOH}$, and $\mathrm{Fe}_{3} \mathrm{O}_{4} @ \mathrm{SiO}_{2}-\mathrm{NH}_{2} @ \mathrm{NIP}$ are displayed in Fig. S1. $\dagger$ The $\mathrm{Fe}_{3} \mathrm{O}_{4}$ in $\mathrm{Fe}_{3} \mathrm{O}_{4} @ \mathrm{SiO}_{2}-\mathrm{COOH} @ \mathrm{MIP}$ (Fig. 1c) and $\mathrm{Fe}_{3} \mathrm{O}_{4} @ \mathrm{SiO}_{2}-$ $\mathrm{COOH} @ \mathrm{NIP}$ (Fig. 1d) is seriously agglomerated, and isolated magnetic microspheres are completely invisible. However, although the $\mathrm{Fe}_{3} \mathrm{O}_{4}$ in MMIP modified with amino groups (Fig. 1a) is agglomerated, single magnetic microspheres can still be observed.

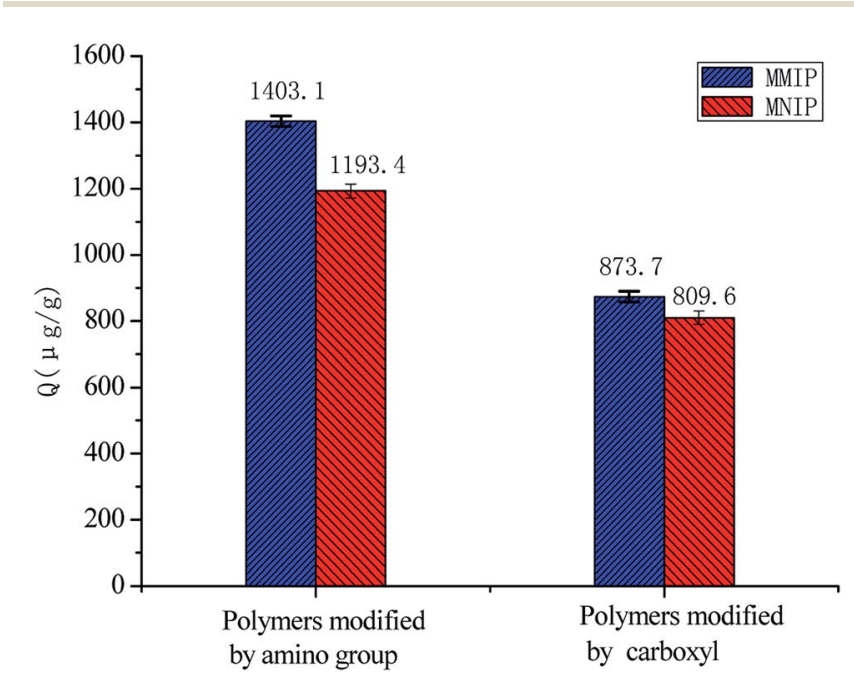

Fig. 4 Comparison of the capacity of polymers modified by amino and carboxyl groups.

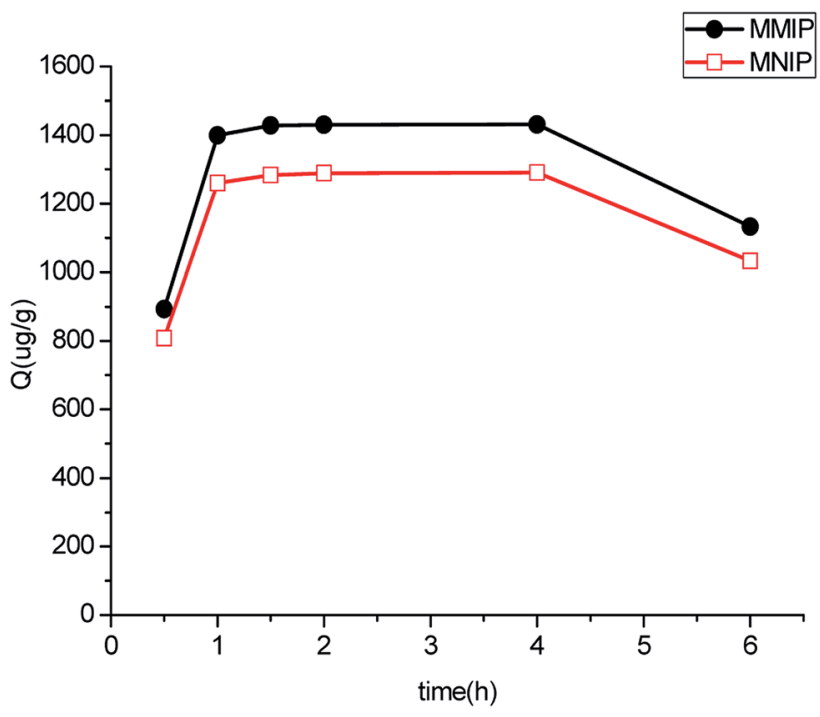

Fig. 5 Kinetics adsorption curve of MMIP and MNIP.

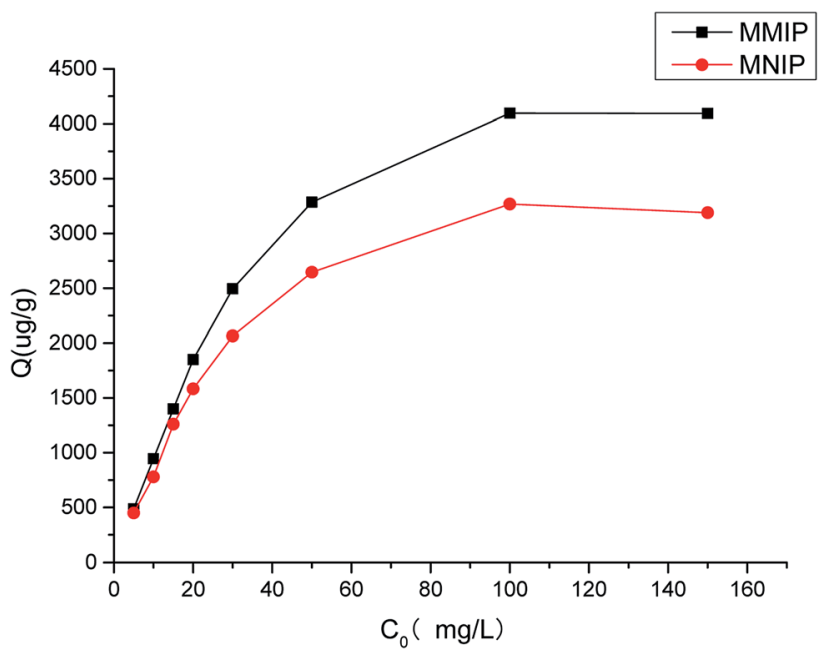

Fig. 6 Isothermal adsorption curve of MMIP and MNIP.

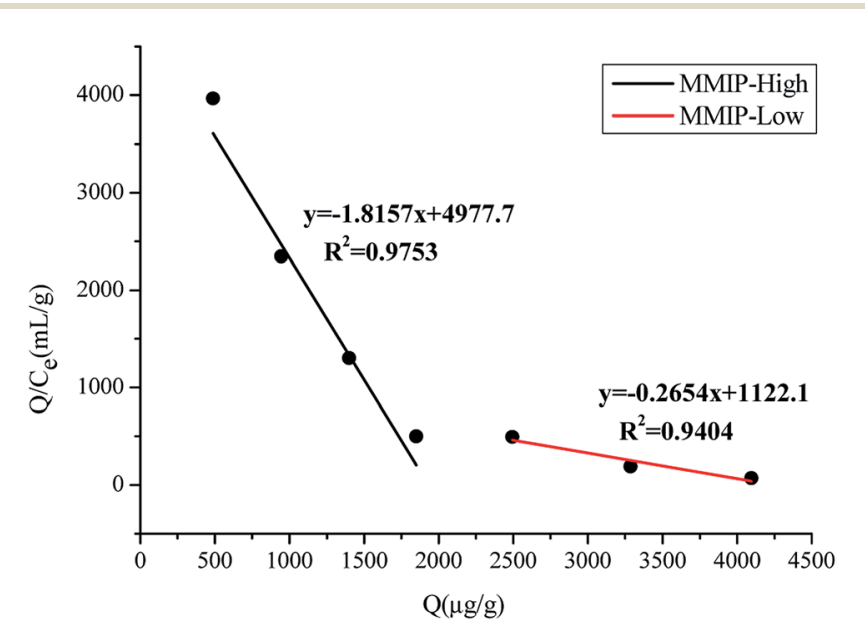

Fig. 7 Scatchard equation of MMIP. 
a
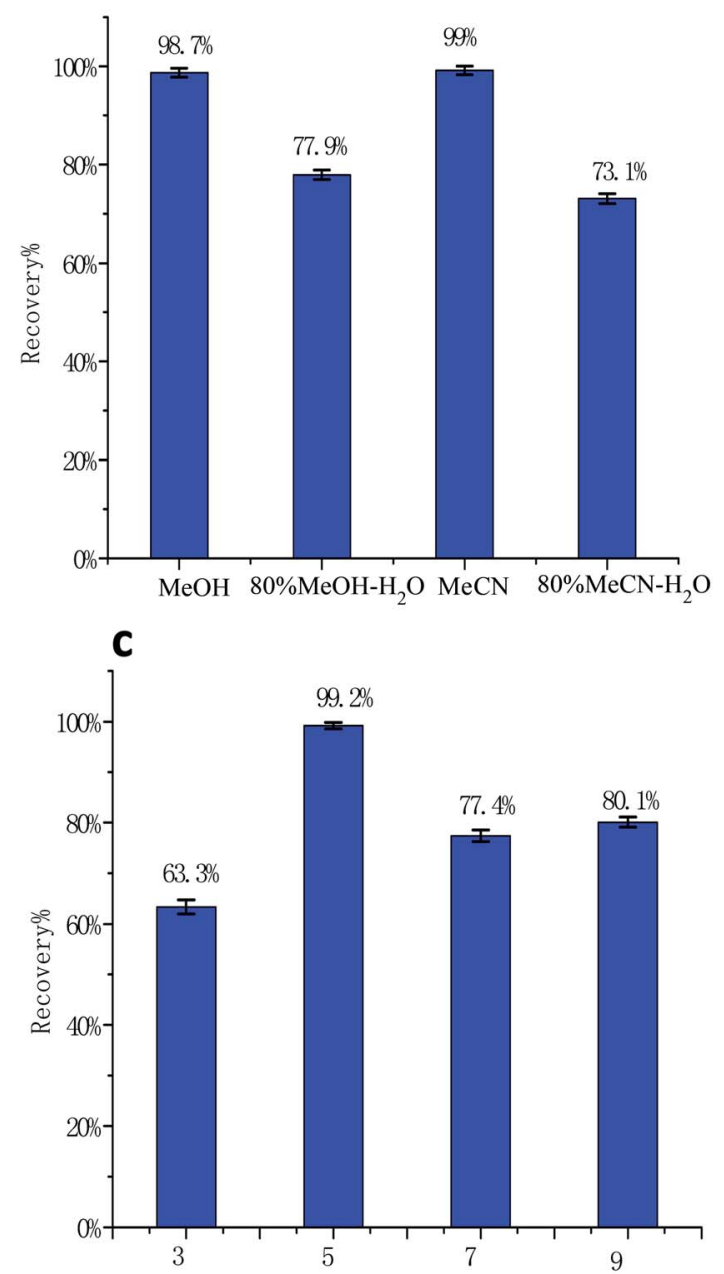

b
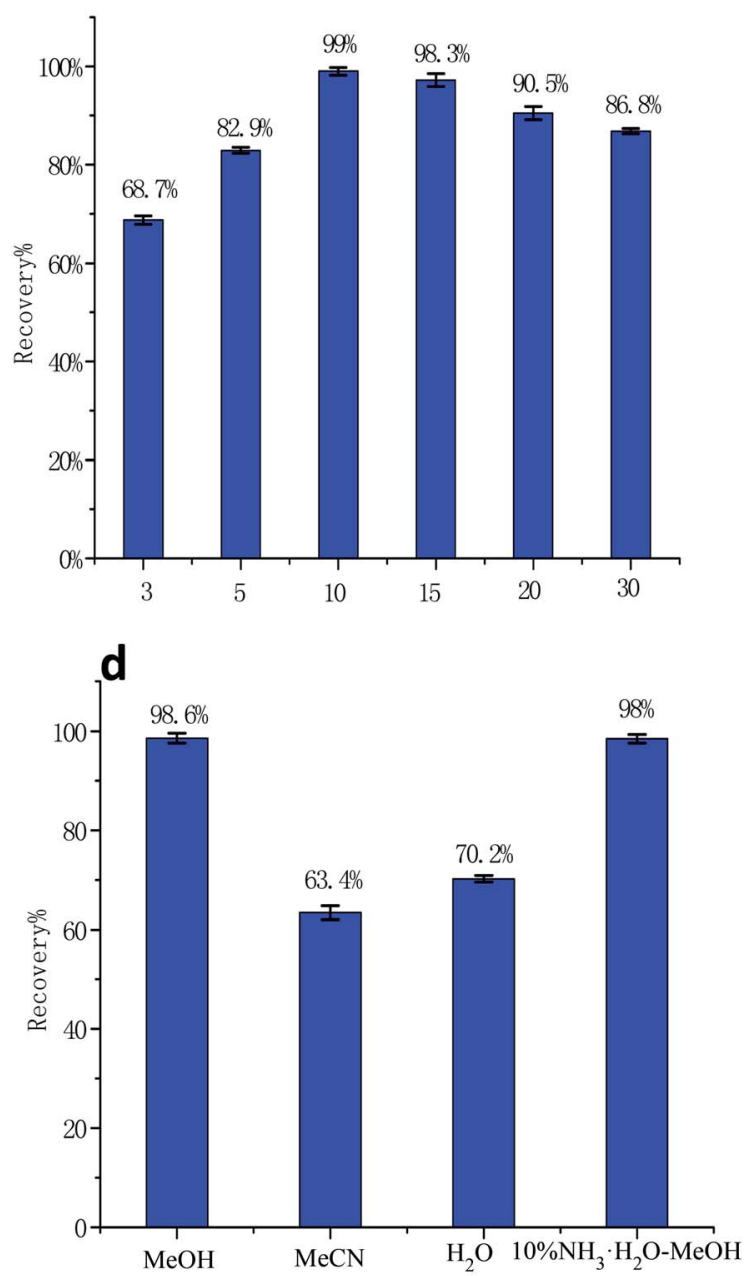

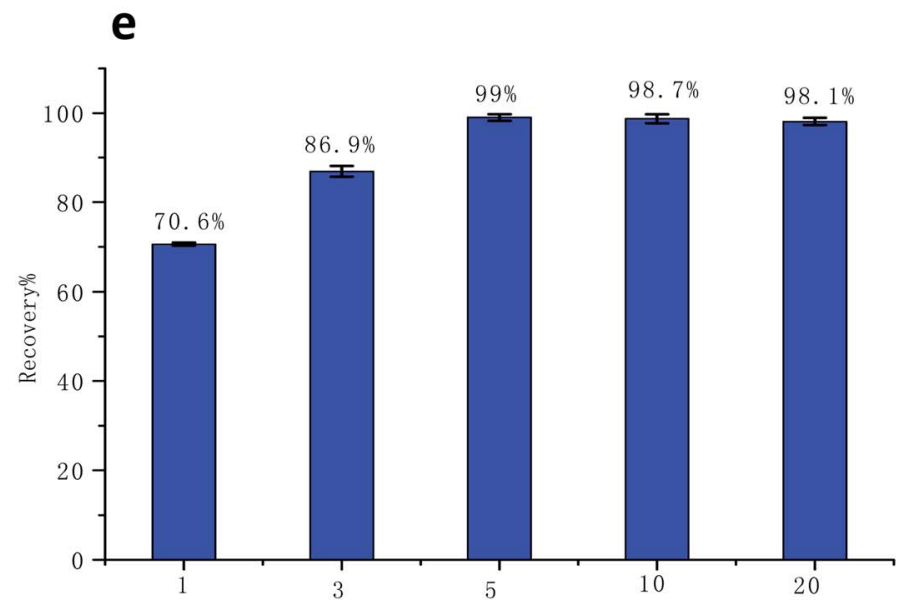

Fig. 8 Effect of different extracts (a), extraction time (b), pH (c), eluent (d), and elution time (e) on the recovery of aminopyralid in milk samples.

Similar to the polymers modified with carboxyl groups, $\mathrm{Fe}_{3} \mathrm{O}_{4}$ @$\mathrm{SiO}_{2}-\mathrm{NH}_{2} @ \mathrm{NIP}$ (Fig. 1b) also has agglomerated $\mathrm{Fe}_{3} \mathrm{O}_{4}$. The prepared $\mathrm{Fe}_{3} \mathrm{O}_{4}$ particles are approximately $10 \mathrm{~nm}$ in diameter and the particle size increases 10 -fold to $100 \mathrm{~nm}$ after molecular imprinting. This may indicate that $\mathrm{Fe}_{3} \mathrm{O}_{4} @ \mathrm{SiO}_{2}-\mathrm{NH}_{2} @ \mathrm{MIP}$ is more suitable than $\mathrm{Fe}_{3} \mathrm{O}_{4} @ \mathrm{SiO}_{2}-\mathrm{COOH} @ \mathrm{MIP}$ for dispersive SPE. 
Although the black $\mathrm{Fe}_{3} \mathrm{O}_{4}$ particle is surrounded by a layer of grey, this does not mean that the grey layer is the molecularly imprinted layer; this layer may also be composed of $\mathrm{SiO}_{2}$. So further characterization is needed to show that the polymer has been successfully polymerized using FT-IR analysis (Fig. 2). The absorption peak at approximately $585.91 \mathrm{~cm}^{-1}$ is related to $\mathrm{Fe}-$ $\mathrm{O}$ vibrations (Fig. $2 \mathrm{~A}(\mathrm{a})$ and $\mathrm{B}(\mathrm{a})$ ). A strong characteristic $\mathrm{Si}-\mathrm{O}$ stretching vibration peak at $1081.52 \mathrm{~cm}^{-1}$ appeared for $\mathrm{Fe}_{3^{-}}$ $\mathrm{O}_{4} @ \mathrm{SiO}_{2}$ (Fig. 2A(b) and $\mathrm{B}(\mathrm{b})$ ), which indicated that $\mathrm{SiO}_{2}$ was successfully coating the surface of $\mathrm{Fe}_{3} \mathrm{O}_{4}$. The peaks at $1626.5 \mathrm{~cm}^{-1}$ and $1720 \mathrm{~cm}^{-1}$ were attributed to the stretching vibrations of the amino group in $\mathrm{Fe}_{3} \mathrm{O}_{4} @ \mathrm{SiO}_{2}-\mathrm{NH}_{2}$ (Fig. $2 \mathrm{~A}(\mathrm{c})$ ) and of the carboxyl group in $\mathrm{Fe}_{3} \mathrm{O}_{4} @ \mathrm{SiO}_{2}-\mathrm{COOH}$ (Fig. 2B(c)), respectively, indicating successful modification with $\mathrm{NH}_{2}$ and $\mathrm{COOH}$ groups on the $\mathrm{Fe}_{3} \mathrm{O}_{4} @ \mathrm{SiO}_{2}$ surface. In the FT-IR spectra of $\mathrm{Fe}_{3} \mathrm{O}_{4} @ \mathrm{SiO}_{2}-\mathrm{NH}_{2} @ \mathrm{MIP}$ (Fig. 2A(d)) and $\mathrm{Fe}_{3} \mathrm{O}_{4} @ \mathrm{SiO}_{2}-$ COOH@MIP (Fig. 2B(d)), the absorption peaks of -OH groups at $3477.21 \mathrm{~cm}^{-1}, \mathrm{C}=\mathrm{O}$ groups at $1720 \mathrm{~cm}^{-1}$ and $\mathrm{C}=\mathrm{C}$ groups at $1598.03 \mathrm{~cm}^{-1}$ indicated the successful grafting of a polymer layer on the $\mathrm{Fe}_{3} \mathrm{O}_{4} @ \mathrm{SiO}_{2}-\mathrm{NH}_{2}$ and $\mathrm{Fe}_{3} \mathrm{O}_{4} @ \mathrm{SiO}_{2}-\mathrm{COOH}$ particles.

The XRD patterns of the nanoparticles are presented in Fig S2a and $b$. $\uparrow$ The pattern of $\mathrm{Fe}_{3} \mathrm{O}_{4}$ has six characteristic peaks at $2 \theta=30.18,35.57,43.16,53.45,57.04$ and 62.67 corresponding to the (220), (311), (400), (422), (511) and (440) crystal faces, ${ }^{26}$ respectively. We can see that the intensities of the peaks are weakened, but the characteristic peak positions did not change, showing that $\mathrm{Fe}_{3} \mathrm{O}_{4} @ \mathrm{SiO}_{2}-\mathrm{NH}_{2} @ \mathrm{MIP}$ and $\mathrm{Fe}_{3} \mathrm{O}_{4} @ \mathrm{SiO}_{2}-\mathrm{COOH}$ comprised $\mathrm{Fe}_{3} \mathrm{O}_{4}$ nanoparticles and that the XRD phase of $\mathrm{Fe}_{3} \mathrm{O}_{4}$ with an inverse spinel structure did not change during the synthesis.

The magnetic properties of the synthesized particles were analysed by VSM, and the results are illustrated in Fig. 3. It is obvious that $\mathrm{Fe}_{3} \mathrm{O}_{4}$ showed no hysteresis, indicating that $\mathrm{Fe}_{3} \mathrm{O}_{4}$ was superparamagnetic. ${ }^{27}$ However, hysteresis was observed after coating with $\mathrm{SiO}_{2}$ and modifying with $\mathrm{NH}_{2}$ and $\mathrm{COOH}$ groups. The composite material can have a certain cohesive force, and the saturation magnetization of $\mathrm{Fe}_{3} \mathrm{O}_{4} @ \mathrm{SiO}_{2}, \mathrm{Fe}_{3^{-}}$ $\mathrm{O}_{4} @ \mathrm{SiO}_{2}-\mathrm{NH}_{2}, \quad \mathrm{Fe}_{3} \mathrm{O}_{4} @ \mathrm{SiO}_{2}-\mathrm{COOH}, \mathrm{Fe}_{3} \mathrm{O}_{4} @ \mathrm{SiO}_{2}-\mathrm{NH}_{2} @ \mathrm{MIP}$ and $\mathrm{Fe}_{3} \mathrm{O}_{4} @ \mathrm{SiO}_{2}-\mathrm{COOH} @ \mathrm{MIP}$ gradually decreased from 72.67 to $36.96,35.82,29.01,13.72$, and $11.93 \mathrm{emu} \mathrm{g}^{-1}$, respectively. These results showed not only that the MMIPs were prepared successfully but also that the prepared polymers have good magnetic properties and can be applied in dispersive SPE for the rapid detection of compounds from solution.

\subsection{Adsorption properties of the MMIP}

Fig. 4 shows the capacity of $10 \mathrm{mg}$ of polymers modified by amino and carboxyl groups for adsorbing a $15 \mu \mathrm{g} \mathrm{mL} \mathrm{m}^{-1}$ aminopyralid solution in methanol. We observed that the amount adsorbed onto polymer surface modified by amino groups was much higher than that with carboxyl groups. This finding might be attributed to electrostatic interaction between MIP and template molecule modified by $\mathrm{Fe}_{3} \mathrm{O}_{4} @ \mathrm{SiO}_{2}-\mathrm{NH}_{2}$ and $\mathrm{Fe}_{3}$ $\mathrm{O}_{4} @ \mathrm{SiO}_{2}-\mathrm{COOH}$. Furthermore, the electrostatic interaction between MIP and template molecule modified by carboxyl was quite weak compared with amino. The adsorption capacity of the MMIP with different amounts of $\mathrm{Fe}_{3} \mathrm{O}_{4} @ \mathrm{SiO}_{2}-\mathrm{NH}_{2}(50,100$, 150 , and $200 \mathrm{mg}$ ) was evaluated. When $100 \mathrm{mg}$ of $\mathrm{Fe}_{3} \mathrm{O}_{4} @ \mathrm{SiO}_{2}-$ $\mathrm{NH}_{2}$ was dispersed in a sample solution, the amount of aminopyralid adsorbed to the MMIP reached a maximum. Due to the occupation of the binding sites of the polymer, the adsorption decreases as the quantity of magnetic nanoparticles increases.

Dynamic binding experiments were performed to determine the adsorption saturation time of polymers, and the results are shown in Fig. 5. The amount of aminopyralid adsorbed to $\mathrm{Fe}_{3}$ $\mathrm{O}_{4} @ \mathrm{SiO}_{2}-\mathrm{NH}_{2} @ \mathrm{MIP}$ reached equilibrium at $1 \mathrm{~h}$ and desorption occurred when the shaking time exceeded $4 \mathrm{~h}$, suggesting that the adsorption is fast.

Fig. 6 shows the static binding isotherms of aminopyralid on MMIP and MNIP. The adsorption capacities of the MMIP and MNIP increased with an increasing initial concentration of aminopyralid. The difference between the MMIP and MNIP at low aminopyralid concentrations was slight, but the absorption of aminopyralid on the MMIP was higher than that on the MNIP at aminopyralid concentrations over $10 \mathrm{mg} \mathrm{L}^{-1}$. This revealed that the MMIP showed a higher binding affinity for aminopyralid than the MNIP. Such a result may be due to the nonspecific adsorption caused by nonspecific recognition sites on the surface of the MNIP being important at low concentrations, while the specific binding sites of MMIP dominated at high concentrations.

The Scatchard equation was calculated and displayed in Fig. 7. It could be concluded that the MMIP provided two different binding sites for adsorption: high and low binding sites. Calculated from the slopes and intercepts of the fitted lines, the $K_{\mathrm{d}}$ values were 0.55 and $3.77 \mu \mathrm{g} \mathrm{mL}{ }^{-1}$, and the $Q_{\max }$ values were 2737.74 and $4226.55 \mu \mathrm{g} \mathrm{g}^{-1}$, respectively.

The adsorption capacity for non-structure analogues (chloramphenicol) and pyridine carboxylic acid (picloram, fluroxypyr and clopyralid) that possessed structural similarities to MMIP was evaluated to determine the selectivity of the MMIP. The results illustrated that the MMIP has almost no adsorption capacity to chloramphenicol due to the lack of imprinted sites specific for compounds with different molecular stereochemistry. The developed MMIP obviously exhibited a high binding affinity for aminopyralid and picloram, while other structurally similar compounds (fluroxypyr, and clopyralid) showed less adsorption affinity as shown in Fig. S3. $\dagger$

The eluted MMIP was reused for five consecutive adsorption-desorption cycles. The results showed that $t$ the adsorption

Table 1 Recoveries, RSD, LOD, and LOQ of aminopyralid in milk samples $(n=3)$

\begin{tabular}{llllll}
\hline \multirow{2}{*}{ Analyte } & $\begin{array}{l}\text { Spiking level } \\
\left(\mu \mathrm{L} \mathrm{L}^{-1}\right)\end{array}$ & $\begin{array}{l}\text { Recovery } \\
(\%)\end{array}$ & $\mathrm{RSD}(\%)$ & $\begin{array}{l}\mathrm{LOD}(\mu \mathrm{g} \\
\left.\mathrm{kg}^{-1}\right)\end{array}$ & $\begin{array}{l}\mathrm{LOQ}(\mu \mathrm{g} \\
\left.\mathrm{kg}^{-1}\right)\end{array}$ \\
\hline \multirow{2}{*}{ Aminopyralid } & 10 & 90 & 12.6 & 0.231 & 0.77 \\
& 20 & 87.4 & 9.8 & & \\
& 50 & 83.3 & 10.2 & &
\end{tabular}


Table 2 Comparison between different detection methods of aminopyralid

\begin{tabular}{|c|c|c|c|c|c|c|c|}
\hline Method & $\begin{array}{l}\text { Pretreatment } \\
\text { methods }\end{array}$ & Sample & Recovery (\%) & $\begin{array}{l}\text { LOD }(\mu \mathrm{g} \\
\left.\mathrm{kg}^{-1}\right)\end{array}$ & $\begin{array}{l}\mathrm{LOQ}(\mu \mathrm{g} \\
\left.\mathrm{kg}^{-1}\right)\end{array}$ & Analysis time & Ref. \\
\hline LC-MS/MS & QuEChERS $^{a}$ & $\begin{array}{l}\text { Cucumber, eggplant, tomato, apple, } \\
\text { grape }\end{array}$ & $70.0-109.4 \%$ & $10-90$ & $21-36$ & $1.5 \mathrm{~h}$ & Tian et al., 2012 \\
\hline GC-ECD & $\mathrm{SPE}^{b}$ & Forage grass, hay, soil & $80.0-104 \%$ & $10-20$ & $20-50$ & $2 \mathrm{~h}$ & Li et al., 2018 \\
\hline LC-MS/MS & $\mathrm{SPE}^{b}$ & Barley & $76.5-88.4 \%$ & 10 & 50 & $2 \mathrm{~h}$ & Zhang et al., 2014 \\
\hline LC-MS/MS & MI-MDSPE $^{c}$ & Milk & $83.3-90 \%$ & 0.231 & 0.77 & $1 \mathrm{~h}$ & This work \\
\hline
\end{tabular}

capacity of aminopyralid on MMIP has little change after seven cycle's regeneration. This finding indicates that MMIP can maintain its excellent affinity and reusability after multiple adsorptions-desorption cycles.

\subsection{Optimization of the MI-MDSPE method}

The MMIP was used in dispersive SPE and the conditions of the MI-MDSPE method were optimized.

3.3.1 Effects of the extraction solution on the recovery. To identify the effect of the extraction solution on the recovery of the target compound; methanol, acetonitrile and their aqueous solutions were tested. As shown in Fig. 8a, the recoveries were higher using methanol and acetonitrile as the extraction solution; however, the presence of water in the solvent would cause poor recoveries. Therefore, in the preparation of milk samples, water must be removed. Considering that the analyte was extracted from milk with acetonitrile, we have chosen acetonitrile as an extraction solvent.

3.3.2 Effects of the extraction time on the recovery. Different shaking times from 3 to 30 min were tested to obtain the optimum time for mixing the sorbent and solution. As shown in Fig. 8b, the recovery increased with an increase in extraction time up to $10 \mathrm{~min}$ and threafter slowly decreased with extraction time. Therefore, the optimum extraction time was set at $10 \mathrm{~min}$.

3.3.3 Effects of the $\mathbf{p H}$ on the recovery. The solution $\mathrm{pH}$ could substantially affect the stability of polymer structures and existing forms of analytes. ${ }^{\mathbf{2 4 , 2 8}}$ In this work, sample $\mathrm{pH}$ values ranging from 3 to 9 were studied. As shown in Fig. 8c, the recovery reached $99.2 \%$ when the $\mathrm{pH}$ was $\leq 5$ and then decreased with further increases in $\mathrm{pH}$. The strong interaction between the analyte and MMIP in weakly acidic solution would maintain the stability of the bond between these two species. However, this bond was destroyed by both alkaline and strongly acidic solution. Thus, $\mathrm{pH} 5$ was selected for subsequent experiments.

3.3.4 Effects of the eluent and elution time on the recovery. After determining the optimal extraction solution, extraction time, and $\mathrm{pH}$, the elution solution was optimized. Three millilitres of organic solvent, including methanol, acetonitrile, water, and $10 \%$ ammonium hydroxide-methanol were investigated for coeluting the analyte (Fig. 8d). The results showed that methanol and 10\% ammonium hydroxide-methanol have good elution ability, however, $10 \%$ ammonium hydroxide-methanol was not chosen as the elution solution due to the long nitrogen blowing time and poor environmental protection of ammonium hydroxide. Subsequently, the elution time of the analyte from the MMIP was optimized in the range of 1 to 20 min. As shown in Fig. 8e, the analyte was completely removed from the sorbent at $5 \mathrm{~min}$.

\subsection{Validation of the MI-MDSPE-LC-MS/MS method}

To validate the MI-MDSPE-LC-MS/MS method, analytical performance characteristics such as sensitivity, detection limits, accuracy, precision, and interferences were evaluated.

The linearity of the method was tested by adding different concentrations $\left(1,5,10,20,50\right.$, and $\left.100 \mu \mathrm{g} \mathrm{L}^{-1}\right)$ of aminopyralid to blank milk samples. Good linearities were obtained for analyte with correlation coefficients $\left(R^{2}\right)$ higher than 0.9972 . The LOD $(\mathrm{S} / \mathrm{N}=3)$ and LOQ $(\mathrm{S} / \mathrm{N}=10)$ for aminopyralid were $0.231 \mu \mathrm{g} \mathrm{kg}{ }^{-1}$ and $0.77 \mu \mathrm{g} \mathrm{kg}{ }^{-1}$, respectively, which are sufficient for determination of aminopyralid in milk.

The precision of the developed method was investigated by spiking blank milk samples with aminopyralid at three different concentrations $\left(10,20\right.$, and $\left.50 \mu \mathrm{g} \mathrm{kg} \mathrm{kg}^{-1}\right)$ in triplicates. As complied in Table 1, the recovery rates were ranged from 83.3$90 \%$ with relative standard deviations (RSDs) $<12.6 \%$; the finding which indicates that the MI-MDSPE-LC-MS/MS is a reliable method. Compared with other methods, MI-MDSPELC-MS/MS showed great advantages, especially in terms of LOD (Table 2). Therefore, MMIP has a great potentiality for practical application in detecting aminopyralid in milk samples.

\section{Conclusions}

In this study, MMIPs were synthesized and used as adsorbents in dispersive SPE to adsorb aminopyralid in milk samples prior to determination by LC-MS/MS. MMIPs with a core-shell structure were synthesized by coating dummy molecular template (picloram), functional monomers (4-VP) and crosslinking agent (TRIM) on the surface of $\mathrm{Fe}_{3} \mathrm{O}_{4} @ \mathrm{SiO}_{2}$ modified with amino groups in methanol. Adsorption tests indicated that the MMIP specifically adsorbs aminopyralid. Furthermore, the MMIP was employed in dispersive SPEand the results showed 
that it can be used as an extraction material to detect aminopyralid in milk.

\section{Conflicts of interest}

Authors have declared no conflicts of interest.

\section{Acknowledgements}

This work was supported by the National Natural Science Foundation of China (contract No. 31772071), Guangxi Innovation-Driven Development Project (AA17204043-2), China Agriculture Research System (NO. CARS-05-05A-03), and Central Public-interest Scientific Institution Basal Research Fund (NO. 1610072016009).

\section{References}

1 T. L. Almquist and R. G. Lym, Invasive Plant Sci. Manage., 2017, 3, 155-168.

2 B. Bukun, T. A. Gaines, S. J. Nissen, P. Westra, G. Brunk, D. L. Shaner, B. B. Sleugh and V. F. Peterson, Weed Sci., 2017, 57, 10-15.

3 L. E. Goodman, A. F. Cibils, R. L. Steiner, J. D. Graham and K. C. McDaniel, Invasive Plant Sci. Manage., 2017, 8, 401-408.

4 G. B. Kyser, V. F. Peterson, J. S. Davy and J. M. DiTomaso, Rangel. Ecol. Manag., 2012, 65, 418-425.

5 European Food Safety Authority (EFSA), Italy, EFSA J., 2013, 11, 1-60.

6 J. W. a. S. Ltd, EFSA J., 2016, 14, 1-16.

7 Y. Tian, X. Liu, F. Dong, J. Xu, C. Lu, Z. Kong, Y. Wang and Y. Zheng, J. AOAC Int., 2012, 95, 554-559.

8 W. Li, J. Mao, X. Dai, X. Zhao, C. Qiao, X. Zhang and E. Pu, Ecotoxicol. Environ. Saf., 2018, 155, 17-25.

9 L. Pauling, J. Am. Chem. Soc., 1940, 62, 2643-2657.

10 S. Huang, J. Xu, J. Zheng, F. Zhu, L. Xie and G. Ouyang, Anal. Bioanal. Chem., 2018, 410, 3991-4014.

11 P. Wang, X. Sun, X. Su and T. Wang, Analyst, 2016, 141, 35403553.
12 Y. P. Song, L. Zhang, G. N. Wang, J. X. Liu, J. Liu and J. P. Wang, Food Control, 2017, 82, 233-242.

13 L. Xie, R. Jiang, F. Zhu, H. Liu and G. Ouyang, Anal. Bioanal. Chem., 2014, 406, 377-399.

14 M. M. Tian, D. X. Chen, Y. L. Sun, Y. W. Yang and Q. Jia, $R S C$ Adv., 2013, 3, 22111-22119.

15 M. Wei, X. Yan, S. Liu and Y. Liu, J. Mater. Sci., 2018, 53, 4897-4912.

16 S. Huang, J. Xu, J. Zheng, Z. Fang, L. Xie and G. Ouyang, Anal. Bioanal. Chem., 2018, 410, 1-24.

17 X. Xie, Q. Hu, R. Ke, X. Zhen, Y. Bu and S. Wang, Chem. Eng. J., 2019, 371, 130-137.

18 Y. Xu, Y. Tang, Y. Zhao, R. Gao, J. Zhang, D. Fu, Z. Li, H. Li and X. Tang, J. Colloid Interface Sci., 2018, 515, 18-26.

19 J. L. Benedé, A. Chisvert, D. L. Giokas and A. Salvador, J. Chromatogr. A, 2014, 1362, 25-33.

20 Q. Y. Zhao, H. T. Zhao, X. Yang, H. Zhang, A. J. Dong, J. Wang and B. Li, J. Chromatogr. A, 2018, 1572, 9-19.

21 N. Zou, K. Gu, S. Liu, Y. Hou, J. Zhang, X. Xu, X. Li and C. Pan, J. Sep. Sci., 2016, 39, 1202-1212.

22 S. Wang, B. Wang, H. Si, J. Shan and X. Yang, RSC Adv., 2014, 5, 8028-8036.

23 A. Bazmandegan-Shamili, S. Dadfarnia, A. M. H. Shabani, M. Saeidi and M. R. Moghadam, Food Analytical Methods, 2016, 9, 2621-2630.

24 X. Cao, G. Liu, Y. She, Z. Jiang, F. Jin, M. Jin, P. Du, F. Zhao, Y. Zhang and J. Wang, RSC Adv., 2016, 6, 113144-113151.

25 S. S. Miao, M. S. Wu, H. G. Zuo, C. Jiang, S. F. Jin, Y. C. Lu and H. Yang, J. Agric. Food Chem., 2015, 63, 3634-3645.

26 N. Fangjian, P. Hailong, L. Jinhua, C. Lingxin and X. Hua, J. Agric. Food Chem., 2014, 62, 7436-7443.

27 Y. Li, M. J. Ding, S. Wang, R. Y. Wang, X. L. Wu, T. T. Wen, L. H. Yuan, P. Dai, Y. H. Lin and X. M. Zhou, ACS Appl. Mater. Interfaces, 2011, 3, 3308-3315.

28 Q. Jindong, W. Mingyu, Y. Hongyuan and Y. Gengliang, J. Agric. Food Chem., 2014, 62, 2782-2789. 